\title{
Safety and efficacy of etelcalcetide, an intravenous calcimimetic, for up to 52 weeks in hemodialysis patients with secondary hyperparathyroidism: results of a post-marketing surveillance in Japan
}

\author{
Keitaro Yokoyama ${ }^{1}$ D $\cdot$ Masafumi Fukagawa ${ }^{2} \cdot$ Takashi Shigematsu $^{3} \cdot$ Takashi Akiba $^{4} \cdot$ Ken Yoshikawa $^{5}$. \\ Akira Tsuchiya $^{5} \cdot$ Misato Kuwabara $^{5} \cdot$ Tadao Akizawa $^{6}$
}

Received: 12 March 2020 / Accepted: 16 July 2020 / Published online: 20 August 2020

(c) The Author(s) 2020

\begin{abstract}
Background Etelcalcetide is a second-generation calcimimetic for the management of secondary hyperparathyroidism (SHPT) in patients on dialysis. We performed a post-marketing surveillance (PMS) to obtain information on the safety and efficacy of etelcalcetide in clinical practice in Japan.

Methods This PMS enrolled SHPT patients who started initial treatment with etelcalcetide between April 1, 2017 and February 28, 2018 in Japan. Safety [adverse drug reactions (ADRs)] and efficacy [serum intact parathyroid hormone (iPTH), corrected calcium (cCa), phosphorous (P), and alkaline phosphatase (ALP)] were recorded for up to 52 weeks or until treatment discontinuation. Treatment decisions were at the physician's discretion.

Results Of 1226 patients enrolled across 282 centers, safety and efficacy data were available for 1195 and 1192 , respectively, while 933 continued treatment to Week 52. The starting dose was $5 \mathrm{mg}$ in $82.0 \%$ of patients. There were 218 ADRs in 169 patients (14.1\%). Metabolism and nutrition disorders (8.8\%), adverse laboratory test results $(1.8 \%)$, and gastrointestinal disorders (1.6\%) were the most frequent classes of ADRs. Hypocalcemia-related ADRs occurred in 104 patients $(8.7 \%)$. The percentage of patients with iPTH levels within the target range $(60-240 \mathrm{pg} / \mathrm{mL})$ steadily increased from $19.5 \%$ at Week 0 to $64.1 \%$ at Week 52 or last dose. cCa, P, and ALP levels remained well controlled.

Conclusion This was the first real-world, large-scale, long-term observational PMS of etelcalcetide in Japan. We did not observe any new safety concerns. Etelcalcetide was associated with clinically relevant improvements in serum iPTH and maintenance of serum cCa, P, and ALP levels.
\end{abstract}

Keywords Etelcalcetide $\cdot$ Calcimimetics $\cdot$ Post-marketing surveillance $\cdot$ Hemodialysis $\cdot$ Secondary hyperparathyroidism $\cdot$ Clinical practice

Electronic supplementary material The online version of this article (https://doi.org/10.1007/s10157-020-01936-2) contains supplementary material, which is available to authorized users.

Keitaro Yokoyama

keitaro@jikei.ac.jp

1 Harumi Triton Clinic, The Jikei University Hospital, 1-8-8 Harumi, Chuo-ku, Tokyo 104-0053, Japan

2 Division of Nephrology, Endocrinology and Metabolism, Tokai University School of Medicine, Isehara, Japan

3 Department of Nephrology, Wakayama Medical University, Wakayama, Japan

\section{Introduction}

Secondary hyperparathyroidism (SHPT) is a potential complication of hemodialysis or hemodiafiltration in patients with chronic kidney disease. It is characterized by the excessive

4 Tokyo Next Nephrology and Dialysis Clinic, Tokyo, Japan

5 Department of Pharmacovigilance, Drug Reliability Assurance, ONO Pharmaceutical Co., Ltd., Osaka, Japan

6 Division of Nephrology, Department of Medicine, Showa University School of Medicine, Tokyo, Japan 
release of parathyroid hormone (PTH) from the parathyroid glands in response to a combination of elevated phosphorus $(\mathrm{P})$, decreased calcium $(\mathrm{Ca})$, and decreased 1,25-dihydroxyvitamin D levels, resulting in parathyroid hyperplasia $[1,2]$.

The 2017 Kidney Disease: Improving Global Outcomes (KDIGO) guidelines suggest the use of calcimimetics, calcitriol, vitamin D analogs, or a combination of calcimimetics with calcitriol or vitamin $\mathrm{D}$ analogs for patients on dialysis requiring PTH-lowering therapy. The guidelines also suggest that serum intact PTH (iPTH) levels should be maintained within a range of about two to nine times the assay's upper limit of normal [3]. The Japanese Society for Dialysis Therapy [4] guidelines suggest that serum $\mathrm{P}$ and $\mathrm{Ca}$ levels should be controlled first, followed by the management of serum PTH levels, with a suggested target range of $60-240 \mathrm{pg} /$ $\mathrm{mL}$, using appropriate medical therapy (serum P/Ca management, vitamin $\mathrm{D}$ receptor activators, and/or cinacalcet hydrochloride).

Etelcalcetide is an intravenous calcimimetic agent that activates the calcium-sensing receptor and inhibits the release of PTH from the parathyroid glands, and hence decreases serum Ca levels [5, 6]. Etelcalcetide has been approved in several countries for the treatment of SHPT in patients on hemodialysis. Clinical trials used for the approval of novel drugs remain an important aspect of drug development and approval. However, they may not fully reflect the reality of clinical practice or provide comprehensive insight into the safety of newly approved drugs when used in clinical settings. In particular, clinical trials often exclude some specific categories of patients. For etelcalcetide, the prior trials excluded patients whose last dose of cinacalcet was $<28$ days before starting etelcalcetide, pretreatment serum iPTH was $\leq 240 \mathrm{pg} / \mathrm{mL}$, or serum pretreatment corrected $\mathrm{Ca}$ (cCa) was $<8.4 \mathrm{mg} / \mathrm{dL}$. Moreover, clinical trials are generally small, which may hinder the detection of important but rare adverse drug reactions (ADRs).

Post-marketing surveillance (PMS) can help to overcome these limitations and provide valuable information on the safety and efficacy of newly approved drugs in a large population of patients. Following the approval of etelcalcetide in Japan, a PMS was implemented to investigate its safety and efficacy for managing SHPT in a target population of $\sim 1000$ Japanese patients treated in actual clinical practice. Here, we report the final results of this PMS in patients treated with etelcalcetide for up to 52 weeks.

\section{Methods}

\section{Ethics}

This PMS was conducted as part of the mandatory actions for approval of etelcalcetide in Japan and complied with the
Japanese ministerial ordinance on Good Post-marketing Study Practice. According to this ordinance, ethical approval of the participating medical institutions and patient consent is not required. The PMS was registered on the Japan Pharmaceutical Information Center database (JapicCTI-184074).

\section{Patients}

Patients were to be enrolled in this Japanese PMS if they started treatment with etelcalcetide for the first time to manage SHPT during hemodialysis between April 1, 2017 and February 28, 2018. Patients were enrolled within 14 days of starting treatment of etelcalcetide and followed up for 52 weeks after starting treatment or until discontinuation.

\section{PMS design and treatments}

All treatments were at the physician's discretion with consideration of the approved labels for the prescribed products. In accordance with its package insert, etelcalcetide should be administered intravenously during dialysis at a starting dose of $5 \mathrm{mg}$ three-times-weekly. Its dose can be adjusted across a range of $2.5-15 \mathrm{mg}$ as deemed appropriate by the physician.

The package insert for etelcalcetide in Japan recommends maintaining serum PTH within a control target range, and that its dose can be reduced or its administration stopped if serum PTH falls below the control target level and/or serum cCa decreases to $<8.4 \mathrm{mg} / \mathrm{dL}$. Although no specific serum iPTH level is recommended in the package insert, the Japanese Society for Dialysis Therapy [4] guidelines suggest a target range of $60-240 \mathrm{pg} / \mathrm{mL}$.

The use and dosing of concomitant therapies were at the physician's discretion. The type of dialysate, including the dialysate Ca concentration (2.5-3.0 mEq/L), was dependent on the dialysate used at the institution because most institutions in Japan use a central dialysate delivery system and the dialysate is rarely changed in individual patients.

\section{Data collection and endpoints}

All data were recorded prospectively using an electronic data capture system. Information recorded at enrollment included the date on which etelcalcetide was started. This information was to be enrolled within 14 days of the start of etelcalcetide. The physicians also recorded patient characteristics, dialysis-related variables, history of cinacalcet use, etelcalcetide use, concomitant therapies, laboratory variables, and adverse events (AEs). Additionally, the physicians collected information on the use of concomitant therapies including active vitamin D preparations, Ca preparations, and phosphatebinders, and whether parathyroidectomy or percutaneous ethanol injection therapy were performed. 
Safety was assessed in terms of the rates and types of ADRs, with a special focus on hypocalcemia, worsening of cardiac failure, QT prolongation, hypersensitivity, convulsions, and bone metabolism disorders. ADRs were classified as AEs that were regarded as having a causal relationship with etelcalcetide. ADRs and their severity (serious or nonserious) were primarily assessed by the attending physician. Any AEs that were not considered to be ADRs, and any ADRs that were not deemed to be serious ADRs by the physicians, could be re-classified as ADRs or as serious ADRs, as appropriate, by the sponsor.

Efficacy was evaluated in terms of changes in laboratory variables, focusing on serum iPTH, cCa, $\mathrm{P}$, and alkaline phosphatase (ALP) levels. We also performed subgroup analyses to determine the proportion of patients who achieve serum iPTH levels within the target range.

The cCa levels were calculated by each institution using the following formula, and the values were collected by the sponsor:

$\mathrm{cCa}(\mathrm{mg} / \mathrm{dL})=$ serum $\mathrm{Ca}($ in $\mathrm{mg} / \mathrm{dL})-$ serum albumin (in $\mathrm{g} / \mathrm{dL})+4.0$.

\section{Statistical analyses}

It was planned to enroll about 1200 patients, allowing safety analyses in about 1000 patients. This would enable us to detect unknown ADRs occurring at a frequency of $\geq 0.3 \%$ with a confidence level of $\geq 95 \%$. Assuming each institution/ department enrolled 5-10 patients, it was planned to enlist 120-240 participating medical institutions.

Descriptive statistics (number of patients, mean \pm standard deviation, median [quartile 1-quartile 3], max, minimum) were determined for safety and efficacy variables. The percentages of patients with any ADR, with hypocalcemia, or who achieved serum iPTH within the target range (60-240 pg/mL) were determined together with $95 \%$ confidence intervals. These percentages were calculated for the overall population of patients and in prespecified subgroups of patients divided by baseline characteristics (sex, age, dry body weight, iPTH, cCa, P, ALP, history of dialysis, dialysis modality, dialysate $\mathrm{Ca}$ level, cinacalcet use within 28 days before starting etelcalcetide, and dose of last cinacalcet). Fisher's exact test or the Mann-Whitney $U$ test were performed as appropriate for subgroup analysis.

We performed logistic regression analyses using the appearance of hypocalcemia as an objective variable and possible factors affecting hypocalcemia as explanatory variables, which were selected using the forward-backward stepwise selection method, in the safety analysis set. We also performed logistic regression analyses using the proportion of patients who achieved serum iPTH within the target range as an objective variable, and selected possible explanatory factors using the forward-backward stepwise selection method, in the efficacy analysis set.

SAS version 9.4 (SAS Institute, Cary, NC, USA) and Microsoft Excel 2010 (Microsoft, Redmond, VA, USA) were used for all analyses.
Fig. 1 Patient disposition. $C R F$ case report form. ${ }^{a}$ Multiple reasons may apply. ${ }^{b}$ Patients whose efficacy data were not measured for all four efficacy endpoints (serum corrected calcium, serum phosphorus, serum intact parathyroid hormone, and serum alkaline phosphatase)

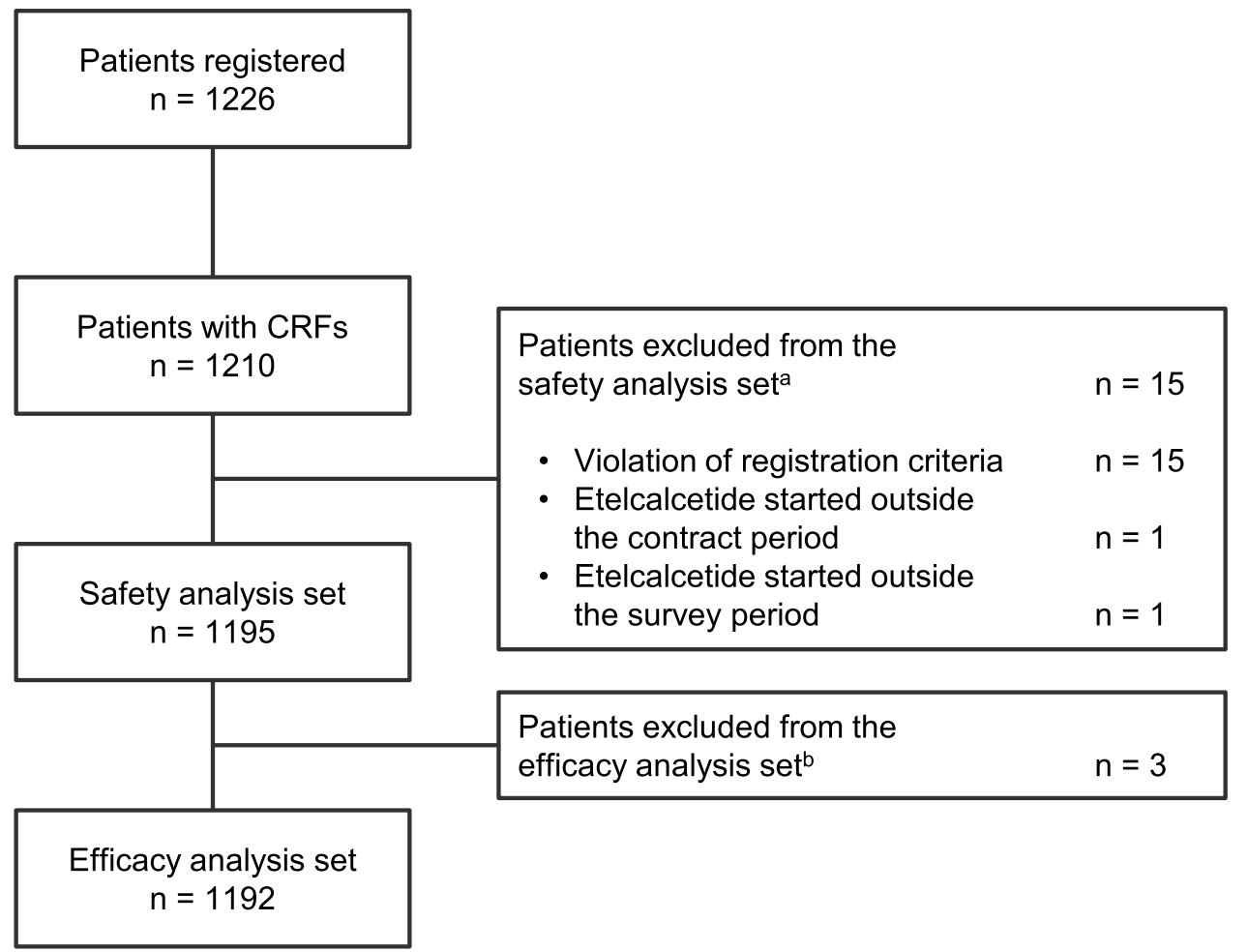




\section{Results}

\section{Patients and treatments}

A total of 1226 patients, at 282 dialysis centers, were enrolled between April 1, 2017 and February 28, 2018. Data collection was completed on August 31, 2019. Electronic case report forms were available for 1210 patients, of which 15 were excluded from the safety analysis set and a further three patients were excluded from the efficacy analysis set (Fig. 1). Therefore, the safety analysis set comprised 718 males and 477 females (Table 1). The mean age and dry weight were 64.5 years and $58.7 \mathrm{~kg}$, respectively, and the median dialysis duration was 8.3 years.

Table 1 Patient characteristics before the start of etelcalcetide $(N=1195)$

\begin{tabular}{ll}
\hline Characteristic & Value $^{\mathrm{a}}$ \\
\hline Male, $n(\%)$ & $718(60.1)$ \\
Female, $n(\%)$ & $477(39.9)$ \\
Age (years) & $64.5 \pm 12.8$ \\
Dry weight $(\mathrm{kg})$ & $58.7 \pm 15.1(n=1184)$ \\
Dialysis duration (years) & $8.3(4.0-14.4)(n=1168)$ \\
Serum iPTH $(\mathrm{pg} / \mathrm{mL})$ & $346.0(255.0-481.0)(n=1087)$ \\
Serum cCa $(\mathrm{mg} / \mathrm{dL})$ & $9.23 \pm 0.73(n=1156)$ \\
Serum P $(\mathrm{mg} / \mathrm{mL})$ & $5.84 \pm 1.48(n=1156)$ \\
Serum ALP $(\mathrm{U} / \mathrm{L})$ & $267.0(208.0-351.0)(n=975)$ \\
\hline
\end{tabular}

$i P T H$ intact parathyroid hormone, $c C a$ corrected calcium, $P$ phosphorus, $A L P$ alkaline phosphatase

${ }^{\text {a }}$ Values are reported as mean \pm standard deviation or median (quartile 1-quartile 3)
The starting dose was $5 \mathrm{mg}$ in most of the patients (Fig. 2). The distribution of etelcalcetide doses changed progressively over time, with steady increases in the percentages of patients administered etelcalcetide at a dose of $2.5 \mathrm{mg}$ or $\geq 7.5 \mathrm{mg}$. The mean dose at Week 52 was $5.1 \mathrm{mg}$. Overall, $78.1 \%$ of patients $(933 / 1195)$ were treated with etelcalcetide at Week 52. None of the patients received etelcalcetide at a dose of $>0$ to $<2.5 \mathrm{mg}$ or at a dose of $>15 \mathrm{mg}$. At the start of treatment, etelcalcetide was administered three-timesweekly in 1164 patients (97.4\%), twice-weekly in 20 patients $(1.7 \%)$, and once-weekly in 11 patients $(0.9 \%)$. At Week 52 or the last dosing day, etelcalcetide was administered threetimes-weekly in 1078 patients $(90.2 \%)$, twice-weekly in 64 patients (5.4\%), and once-weekly in 47 patients (3.9\%), and drug cessation in 6 patients $(0.5 \%)$. Active vitamin D preparations and anti-hyperphosphatemia drugs were used as concomitant therapies (at least once during the treatment period) in $89.8 \%$ and $88.3 \%$ of patients, respectively.

\section{Incidence of ADRs}

A total of 218 ADRs occurred in 169 patients (14.1\%), including 36 serious ADRs in 28 patients (2.3\%). Metabolism and nutrition disorders was the most common class of ADRs followed by laboratory tests and gastrointestinal disorders (Table 2). The types of ADRs are summarized in ESM Table 1. ADRs of special interest included ADRs related to hypocalcemia in 104 patients (8.7\%), hypersensitivity reactions in six patients $(0.5 \%)$, QT prolongation in two patients $(0.2 \%)$, and worsening of cardiac failure and convulsions in one patient each $(0.1 \%)$ (Table 2). As illustrated in Fig. 3, the cumulative incidence of all ADRs and hypocalcemia increased over the first $\sim 32$ weeks and then plateaued until the end of the follow-up period.
Fig. 2 Changes in etelcalcetide doses over time

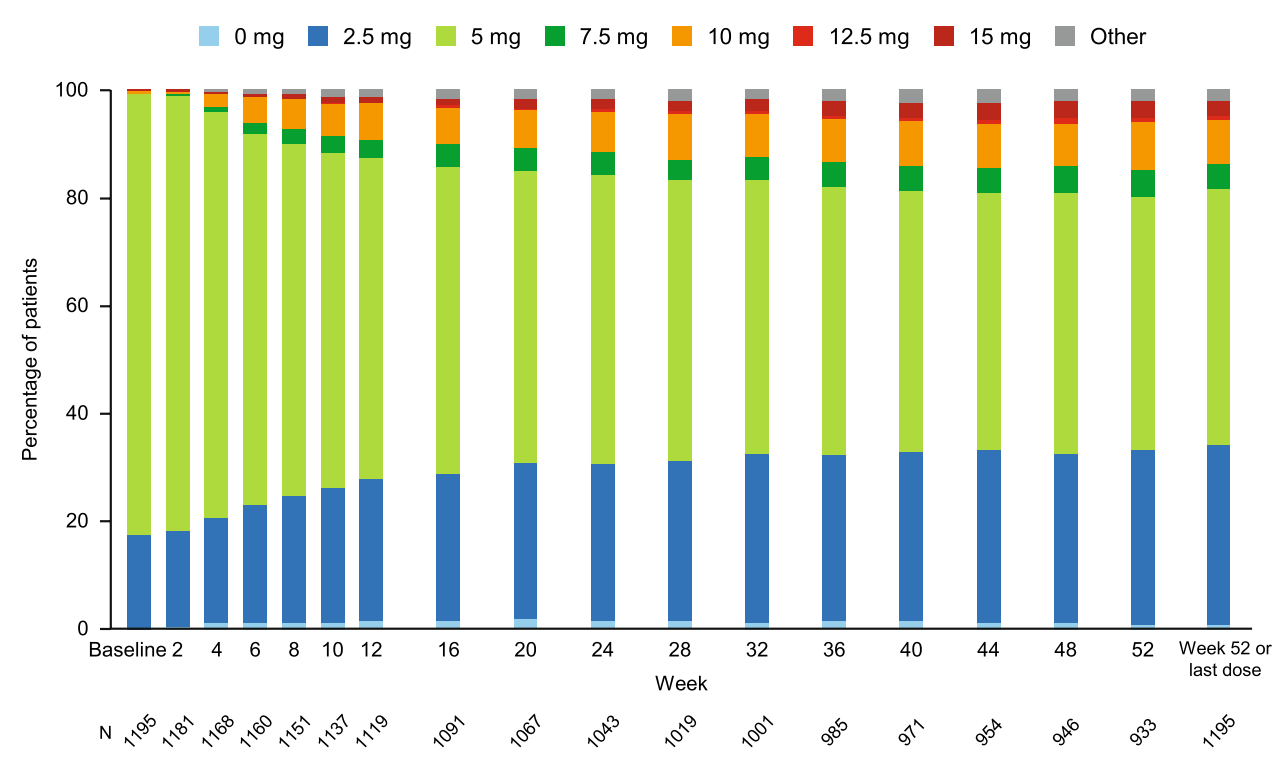


Table 2 ADRs by system organ class and of special interest $(N=1195)$

\begin{tabular}{|c|c|c|c|}
\hline Classification & Serious & Non-serious & Total \\
\hline Number of subjects with ADRs & 28 & 150 & 169 \\
\hline Number of ADRs & 36 & 182 & 218 \\
\hline Incidence of ADRs (\%) & 2.3 & 12.6 & 14.1 \\
\hline \multicolumn{4}{|l|}{ ADR by system organ class, $n(\%)$} \\
\hline Metabolism and nutrition disorders & $1(0.1)$ & $104(8.7)$ & $105(8.8)$ \\
\hline Laboratory tests & $1(0.1)$ & $21(1.8)$ & $22(1.8)$ \\
\hline Gastrointestinal disorders & $5(0.4)$ & $14(1.2)$ & $19(1.6)$ \\
\hline Nervous system disorders & $5(0.4)$ & $5(0.4)$ & $10(0.8)$ \\
\hline Musculoskeletal and connective tissue disorders & $2(0.2)$ & $5(0.4)$ & $7(0.6)$ \\
\hline Skin and subcutaneous tissue disorders & $1(0.1)$ & $6(0.5)$ & $7(0.6)$ \\
\hline Infections and infestations & $3(0.3)$ & $3(0.3)$ & $6(0.5)$ \\
\hline Cardiac disorders & $3(0.3)$ & $2(0.2)$ & $5(0.4)$ \\
\hline $\begin{array}{l}\text { General/systemic disorders and administration site } \\
\text { conditions }\end{array}$ & $1(0.1)$ & $3(0.3)$ & $4(0.3)$ \\
\hline Hepatobiliary disorders & $1(0.1)$ & $2(0.2)$ & $3(0.3)$ \\
\hline Injury, poisoning and procedural complications & $2(0.2)$ & $1(0.1)$ & $2(0.2)$ \\
\hline Neoplasms benign, malignant and unspecified & $2(0.2)$ & - & $2(0.2)$ \\
\hline Vascular disorders & $2(0.2)$ & - & $2(0.2)$ \\
\hline Blood and lymphatic system disorders & - & $2(0.2)$ & $2(0.2)$ \\
\hline Ear and labyrinth disorders & $1(0.1)$ & - & $1(0.1)$ \\
\hline Respiratory, thoracic and mediastinal disorders & $1(0.1)$ & - & $1(0.1)$ \\
\hline Eye disorders & - & $1(0.1)$ & $1(0.1)$ \\
\hline Psychiatric disorders & - & $1(0.1)$ & $1(0.1)$ \\
\hline \multicolumn{4}{|l|}{ ADRs of special interest, $n(\%)$} \\
\hline ADRs related to hypocalcemia & - & $104(8.7)$ & $104(8.7)$ \\
\hline Hypocalcemia & - & $92(7.7)$ & $92(7.7)$ \\
\hline Blood calcium decreased & - & $10(0.8)$ & $10(0.8)$ \\
\hline Adjusted calcium decreased & - & $2(0.2)$ & $2(0.2)$ \\
\hline Hypersensitivity reactions & $1(0.1)$ & $5(0.4)$ & $6(0.5)$ \\
\hline Drug eruption & $1(0.1)$ & $1(0.1)$ & $2(0.2)$ \\
\hline Eczema & - & $2(0.2)$ & $2(0.2)$ \\
\hline Rash & - & $1(0.1)$ & $1(0.1)$ \\
\hline Rash generalized & - & $1(0.1)$ & $1(0.1)$ \\
\hline QT prolongation & $1(0.1)$ & $1(0.1)$ & $2(0.2)$ \\
\hline Electrocardiogram QT prolonged & $1(0.1)$ & $1(0.1)$ & $2(0.2)$ \\
\hline Worsening of cardiac failure & $1(0.1)$ & - & $1(0.1)$ \\
\hline Cardiac failure & $1(0.1)$ & - & $1(0.1)$ \\
\hline Convulsions & $1(0.1)$ & - & $1(0.1)$ \\
\hline Epilepsy & $1(0.1)$ & - & $1(0.1)$ \\
\hline
\end{tabular}

$A D R$ adverse drug reaction

\section{Patient- and disease-related factors associated with ADRs and hypocalcemia}

Subgroup analyses were performed to identify whether any patient or baseline characteristics were associated with the risk of hypocalcemia or any ADR (Table 3). We found that the incidence of hypocalcemia was significantly higher in patients with a dialysis duration of $<1$ or $\geq 1$ to $<5$ years than in the other subgroups $(P=0.002)$, but there were no differences in the incidence of hypocalcemia among any of the other subgroups assessed. Multiple logistic regression was performed using the following explanatory variables: sex, age, dry weight, baseline serum iPTH, baseline serum $\mathrm{cCa}$, baseline serum P, baseline serum ALP, and dialysis duration. Of these, only age and dialysis duration were independently associated with the risk of hypocalcemia (Table 4). The changes in serum cCa in subgroups of patients who were divided by age or dialysis duration are shown in 
Fig. 3 Cumulative incidence of ADR (any) and hypocalcemia (combination of blood calcium decreased or hypocalcemia). The curves were plotted using the Kaplan-Meier method and tick marks indicate censored patients. $A D R$ adverse drug reaction

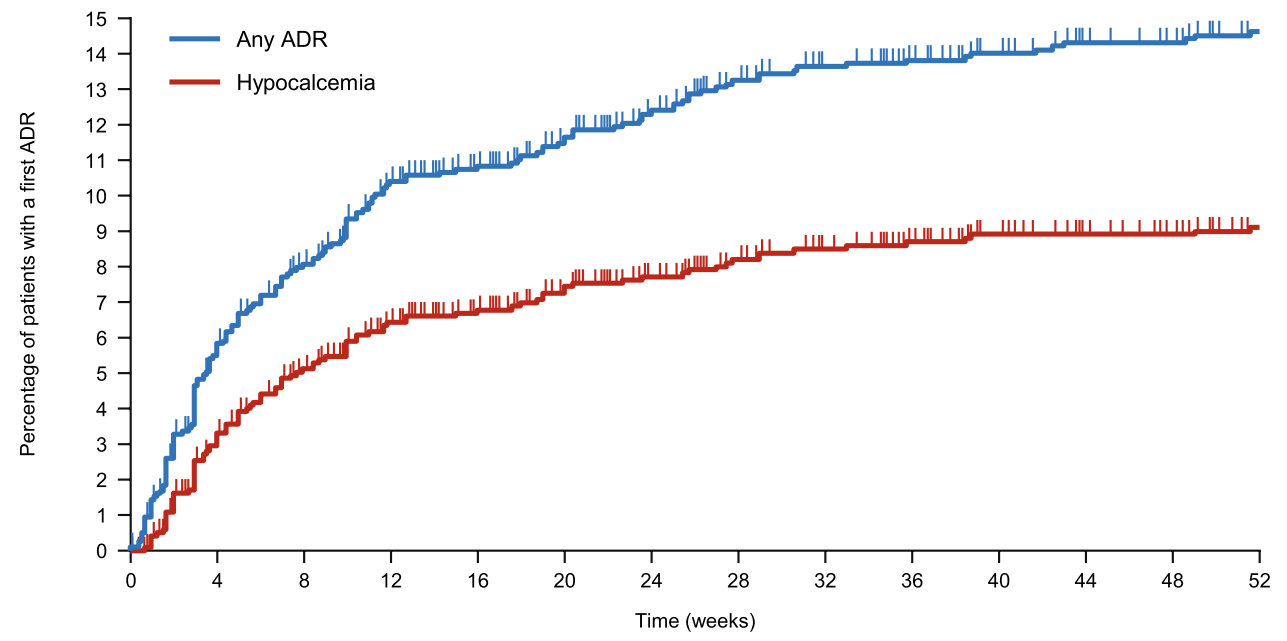

ESM Figs. 1 and 2. The incidence of any ADRs was significantly associated with dialysis duration $(P=0.019)$, but no differences were found among other subgroups (Table 3 ).

\section{Efficacy of etelcalcetide}

The efficacy of etelcalcetide was examined in terms of the changes in serum $\mathrm{PTH}, \mathrm{cCa}, \mathrm{P}$, and ALP levels over time. As shown in Fig. 4a, the serum iPTH level decreased steadily during the follow-up period, reaching a median (quartile 1-quartile 3) of 136.8 (76.0-214.0) pg/mL at Week 52 or last dose. In accordance with these changes in the median serum iPTH level, the proportion of patients who achieved serum iPTH within the target range of $60-240 \mathrm{pg} / \mathrm{mL}$ steadily increased from $19.5 \%$ at Week 0 to $64.1 \%$ at Week 52 or last dose (Fig. 4b). Although the proportion of responders was significantly greater among patients with a baseline serum iPTH level $\leq 240 \mathrm{pg} / \mathrm{mL}(72.8 \%)$ than in patients with higher baseline levels $(P<0.001)$, the proportion was over $50 \%$ among patients with baseline levels of $>240$ to $<500 \mathrm{pg} / \mathrm{mL}(67.8 \%)$ or $\geq 500 \mathrm{pg} / \mathrm{mL}$ (53.5\%) (Table 5). The proportion of responders was also significantly greater in patients with low baseline serum ALP levels $(P=0.044)$ (Table 5).

Multiple logistic regression was performed to identify possible factors associated with achievement of serum iPTH within the target range using the following explanatory variables: sex, age, dry weight, baseline iPTH, baseline cCa, baseline P, baseline ALP, and dialysis duration. Of these, only the baseline iPTH level was independently associated with the proportion of patients who achieved $\mathrm{PPTH}$ within the target range (Table 4).

In terms of other efficacy outcomes, we found that the mean serum $\mathrm{cCa}$ and $\mathrm{P}$ levels remained within their target ranges throughout the follow-up period (Fig. 4c, d). We also observed improvements in serum ALP levels (Fig. 4e).
This PMS enrolled patients who were ineligible for the previous long-term clinical study in Japan (52-week study) [7], including patients whose last dose of cinacalcet was $<28$ days before the start of etelcalcetide, patients with a baseline serum iPTH of $\leq 240 \mathrm{pg} / \mathrm{mL}$, and patients with a baseline serum cCa of $<8.4 \mathrm{mg} / \mathrm{dL}$. The changes in serum $\mathrm{iPTH}, \mathrm{cCa}, \mathrm{P}$, and ALP in these subgroups of patients are shown in ESM Figs. 3-5.

\section{Discussion}

This was the first real-world, large-scale, long-term observational PMS to examine the safety and efficacy of etelcalcetide for the management of SHPT. The rates of ADRs (14.1\%) and serious ADRs (2.3\%) do not exceed the levels reported in the 52-week study (ADRs, 27.9\%; serious ADRs, 2.1\%) [7].

Hypocalcemia, a calcimimetic-related AE, was the most common ADR as hypocalcemia-related ADRs occurred in 104 patients (8.7\%). Other ADRs of special interest included hypersensitivity reactions, worsening of cardiac failure, QT prolongation, and convulsions, all of which were infrequent and have already been described in the package insert for etelcalcetide. It was suggested in earlier studies that the injectable formulation of etelcalcetide might contribute to a lower rate or decreased severity $[7,8]$ of gastrointestinal disorder-related ADRs, and a similar trend was observed in the present PMS.

From an efficacy perspective, we observed gradual reductions in serum iPTH that were not too rapid. At Week 52 or last dose, $64.1 \%$ of patients had a serum iPTH of $60-240 \mathrm{pg} /$ $\mathrm{mL}$. In the prior 52 -week study, $87.5 \%$ of patients achieved serum iPTH levels of 60-240 pg/mL [7]. The higher proportion of patients achieving target iPTH levels in that study is likely due to the treatment protocol, which required adjustment of the etelcalcetide dose according to the patient's iPTH level to reach the target range. These improvements 
Table 3 Subgroup analysis of hypocalcemia and ADRs $(N=1195)$

\begin{tabular}{|c|c|c|c|c|c|c|c|c|}
\hline \multicolumn{3}{|l|}{ Characteristic } & \multicolumn{3}{|c|}{ Hypocalcemia } & \multicolumn{3}{|c|}{ Any ADR } \\
\hline Variable & Subgroup & $N(\%)$ & $n$ & $\%(95 \% \mathrm{CI})$ & $P$ & $n$ & $\%(95 \% \mathrm{CI})$ & $P$ \\
\hline All patients & & $1195(100.0)$ & 104 & $8.7(7.2-10.4)$ & - & 169 & $14.1(12.2-16.2)$ & - \\
\hline \multirow[t]{2}{*}{ Sex } & Male & $718(60.1)$ & 63 & $8.8(6.8-11.1)$ & $1.000^{\mathrm{a}}$ & 101 & 14.1 (11.6-16.8) & $0.933^{\mathrm{a}}$ \\
\hline & Female & 477 (39.9) & 41 & $8.6(6.2-11.5)$ & & 68 & $14.3(11.2-17.7)$ & \\
\hline \multirow[t]{4}{*}{ Age (years) } & $<55$ & $281(23.5)$ & 33 & $11.7(8.2-16.1)$ & $0.089^{b}$ & 47 & $16.7(12.6-21.6)$ & $0.240^{\mathrm{b}}$ \\
\hline & 55 to $<65$ & $238(19.9)$ & 21 & $8.8(5.5-13.2)$ & & 34 & $14.3(10.1-19.4)$ & \\
\hline & 65 to $<75$ & $422(35.3)$ & 29 & $6.9(4.7-9.7)$ & & 53 & $12.6(9.6-16.1)$ & \\
\hline & $\geq 75$ & $254(21.3)$ & 21 & $8.3(5.2-12.4)$ & & 35 & $13.8(9.8-18.6)$ & \\
\hline \multirow[t]{7}{*}{ Dry body weight (kg) } & $<40$ & $86(7.2)$ & 9 & $10.5(4.9-18.9)$ & $0.516^{\mathrm{b}}$ & 15 & $17.4(10.1-27.1)$ & $0.159^{b}$ \\
\hline & 40 to $<50$ & $285(23.8)$ & 24 & $8.4(5.5-12.3)$ & & 43 & $15.1(11.1-19.8)$ & \\
\hline & 50 to $<60$ & $317(26.5)$ & 32 & $10.1(7.0-14.0)$ & & 47 & $14.8(11.1-19.2)$ & \\
\hline & 60 to $<70$ & $255(21.3)$ & 17 & $6.7(3.9-10.5)$ & & 31 & $12.2(8.4-16.8)$ & \\
\hline & 70 to $<80$ & $136(11.4)$ & 13 & $9.6(5.2-15.8)$ & & 16 & $11.8(6.9-18.4)$ & \\
\hline & $\geq 80$ & $105(8.8)$ & 8 & $7.6(3.3-14.5)$ & & 14 & $13.3(7.5-21.4)$ & \\
\hline & Unknown & $11(0.9)$ & 1 & 9.1 & - & 3 & 27.3 & - \\
\hline \multirow[t]{4}{*}{ Baseline iPTH (pg/mL) } & $\leq 240$ & $226(18.9)$ & 10 & $4.4(2.1-8.0)$ & $0.104^{b}$ & 22 & $9.7(6.2-14.4)$ & $0.107^{\mathrm{b}}$ \\
\hline & $>240$ to $<500$ & $620(51.9)$ & 59 & $9.5(7.3-12.1)$ & & 89 & $14.4(11.7-17.4)$ & \\
\hline & $\geq 500$ & $241(20.2)$ & 21 & $8.7(5.5-13.0)$ & & 36 & $14.9(10.7-20.1)$ & \\
\hline & Unknown & $108(9.0)$ & 14 & 13.0 & - & 22 & 20.4 & - \\
\hline \multirow[t]{4}{*}{ Baseline cCa (mg/dL) } & $<8.4$ & $110(9.2)$ & 10 & $9.1(4.4-16.1)$ & $0.523^{b}$ & 12 & $10.9(5.8-18.3)$ & $0.814^{\mathrm{b}}$ \\
\hline & 8.4 to 10.0 & $904(75.6)$ & 83 & $9.2(7.4-11.3)$ & & 136 & $15.0(12.8-17.5)$ & \\
\hline & $>10.0$ & $142(11.9)$ & 10 & $7.0(3.4-12.6)$ & & 18 & $12.7(7.7-19.3)$ & \\
\hline & Unknown & $39(3.3)$ & 1 & 2.6 & - & 3 & 7.7 & - \\
\hline \multirow[t]{4}{*}{ Baseline P (mg/dL) } & $<3.5$ & $34(2.8)$ & 1 & $2.9(0.1-15.3)$ & $0.467^{\mathrm{b}}$ & 3 & $8.8(1.9-23.7)$ & $0.859^{b}$ \\
\hline & 3.5 to 6.0 & $655(54.8)$ & 58 & $8.9(6.8-11.3)$ & & 96 & $14.7(12.0-17.6)$ & \\
\hline & $>6.0$ & $467(39.1)$ & 44 & $9.4(6.9-12.4)$ & & 67 & $14.3(11.3-17.9)$ & \\
\hline & Unknown & $39(3.3)$ & 1 & 2.6 & - & 3 & 7.7 & - \\
\hline \multirow[t]{4}{*}{ Baseline ALP (U/L) } & $<160$ & $87(7.3)$ & 12 & $13.8(7.3-22.9)$ & $0.965^{b}$ & 17 & $19.5(11.8-29.4)$ & $0.593^{b}$ \\
\hline & $\geq 160$ to $<320$ & $566(47.4)$ & 50 & $8.8(6.6-11.5)$ & & 76 & $13.4(10.7-16.5)$ & \\
\hline & $\geq 320$ & $322(26.9)$ & 34 & $10.6(7.4-14.4)$ & & 55 & $17.1(13.1-21.6)$ & \\
\hline & Unknown & $220(18.4)$ & 8 & 3.6 & - & 21 & 9.5 & - \\
\hline \multirow[t]{6}{*}{ Dialysis duration (years) } & $<1$ & $85(7.1)$ & 10 & $11.8(5.8-20.6)$ & $0.002^{b}$ & 17 & $20.0(12.1-30.1)$ & $0.019^{b}$ \\
\hline & $\geq 1$ to $<5$ & $278(23.3)$ & 39 & $14.0(10.2-18.7)$ & & 44 & $15.8(11.7-20.7)$ & \\
\hline & $\geq 5$ to $<10$ & $314(26.3)$ & 21 & $6.7(4.2-10.0)$ & & 46 & $14.6(10.9-19.1)$ & \\
\hline & $\geq 10$ to $<20$ & $362(30.3)$ & 26 & $7.2(4.7-10.3)$ & & 48 & $13.3(9.9-17.2)$ & \\
\hline & $\geq 20$ & $129(10.8)$ & 7 & $5.4(2.2-10.9)$ & & 11 & $8.5(4.3-14.7)$ & \\
\hline & Unknown & $27(2.3)$ & 1 & 3.7 & - & 3 & 11.1 & - \\
\hline \multirow[t]{2}{*}{ Dialysis modality } & $\mathrm{HD}$ & $795(66.5)$ & 67 & $8.4(6.6-10.6)$ & $0.664^{\mathrm{a}}$ & 108 & $13.6(11.3-16.2)$ & $0.430^{\mathrm{a}}$ \\
\hline & $\mathrm{HDF}$ & $400(33.5)$ & 37 & $9.3(6.6-12.5)$ & & 61 & $15.3(11.9-19.2)$ & \\
\hline \multirow[t]{7}{*}{ Dialysate $\mathrm{Ca}(\mathrm{mEq} / \mathrm{L})$} & $<2.5$ & $7(0.6)$ & 0 & $0.0(0.0-41.0)$ & $0.449^{\mathrm{b}}$ & 0 & $0.0(0.0-41.0)$ & $0.507^{\mathrm{b}}$ \\
\hline & 2.5 & $386(32.3)$ & 30 & $7.8(5.3-10.9)$ & & 50 & $13.0(9.8-16.7)$ & \\
\hline & $>2.5$ to $<2.75$ & $8(0.7)$ & 0 & $0.0(0.0-36.9)$ & & 0 & $0.0(0.0-36.9)$ & \\
\hline & 2.75 & $414(34.6)$ & 38 & $9.2(6.6-12.4)$ & & 64 & $15.5(12.1-19.3)$ & \\
\hline & 3.0 & $355(29.7)$ & 32 & $9.0(6.2-12.5)$ & & 50 & 14.1 (10.6-18.1) & \\
\hline & $>3.0$ & $1(0.1)$ & 0 & $0.0(0.0-97.5)$ & & 0 & $0.0(0.0-97.5)$ & \\
\hline & Unknown & $24(2.0)$ & 4 & 16.7 & - & 5 & 20.8 & - \\
\hline
\end{tabular}


Table 3 (continued)

\begin{tabular}{|c|c|c|c|c|c|c|c|c|}
\hline \multicolumn{3}{|l|}{ Characteristic } & \multicolumn{3}{|c|}{ Hypocalcemia } & \multicolumn{3}{|c|}{ Any ADR } \\
\hline Variable & Subgroup & $N(\%)$ & $n$ & $\%(95 \% \mathrm{CI})$ & $P$ & $n$ & $\%(95 \% \mathrm{CI})$ & $P$ \\
\hline \multirow[t]{4}{*}{ Time since last dose of cinacalcet (days) } & $<7$ & $396(33.1)$ & 29 & $7.3(5.0-10.3)$ & $0.146^{\mathrm{b}}$ & 52 & $13.1(10.0-16.9)$ & $0.704^{b}$ \\
\hline & $\geq 7$ to $<28$ & $137(11.5)$ & 11 & $8.0(4.1-13.9)$ & & 24 & $17.5(11.6-24.9)$ & \\
\hline & $\geq 28$ /cinacalcet-naïve & $647(54.1)$ & 64 & $9.9(7.7-12.5)$ & & 93 & $14.4(11.8-17.3)$ & \\
\hline & Unknown & $15(1.3)$ & 0 & 0.0 & - & 0 & 0.0 & - \\
\hline \multirow[t]{5}{*}{ Last daily dose of cinacalcet $(\mathrm{mg})^{\mathrm{c}}$} & $\leq 25$ & $355(56.7)$ & 28 & $7.9(5.3-11.2)$ & $0.689^{\mathrm{b}}$ & 49 & $13.8(10.4-17.8)$ & $0.992^{\mathrm{b}}$ \\
\hline & $>25$ to $\leq 50$ & $135(21.6)$ & 12 & $8.9(4.7-15.0)$ & & 26 & $19.3(13.0-26.9)$ & \\
\hline & $>50$ to $\leq 75$ & $80(12.8)$ & 5 & $6.3(2.1-14.0)$ & & 10 & $12.5(6.2-21.8)$ & \\
\hline & $>75$ to $\leq 100$ & $51(8.1)$ & 3 & $5.9(1.2-16.2)$ & & 5 & $9.8(3.3-21.4)$ & \\
\hline & Unknown & $5(0.8)$ & 0 & 0.0 & - & 0 & 0.0 & - \\
\hline \multirow[t]{3}{*}{ Liver disease } & No & $1110(92.9)$ & 94 & $8.5(6.9-10.3)$ & $0.063^{\mathrm{a}}$ & 154 & $13.9(11.9-16.0)$ & $0.093^{\mathrm{a}}$ \\
\hline & Yes & $63(5.3)$ & 10 & $15.9(7.9-27.3)$ & & 14 & $22.2(12.7-34.5)$ & \\
\hline & Unknown & $22(1.8)$ & 0 & 0.0 & - & 1 & 4.5 & - \\
\hline \multirow[t]{2}{*}{ Diabetes mellitus } & No & $757(63.3)$ & 69 & $9.1(7.2-11.4)$ & $0.525^{\mathrm{a}}$ & 113 & $14.9(12.5-17.7)$ & $0.343^{\mathrm{a}}$ \\
\hline & Yes & $438(36.7)$ & 35 & $8.0(5.6-10.9)$ & & 56 & $12.8(9.8-16.3)$ & \\
\hline
\end{tabular}

$A D R$ adverse drug reaction, $C I$ confidence interval, $i P T H$ intact parathyroid hormone, $c C a$ corrected calcium, $P$ phosphorus, $A L P$ alkaline phosphatase, $H D$ hemodialysis, $H D F$ hemodiafiltration

${ }^{a}$ Fisher's exact test

${ }^{\mathrm{b}}$ Wilcoxon rank sum test

${ }^{\mathrm{c}} N=626$

Table 4 Multiple logistic regression analyses of factors associated with the occurrence of hypocalcemia in the safety analysis set or achieving iPTH within the target range $(60-240 \mathrm{pg} / \mathrm{mL})$ in the efficacy analysis set

\begin{tabular}{llll}
\hline Outcome: Hypocalcemia & $N$ & Cases $(\%)$ & OR $(95 \%$ CI $)$ \\
\hline $\begin{array}{l}\text { Total } \\
\text { Age }\end{array}$ & 899 & $83(9.2)$ & \\
$\quad<65$ years & 397 & $47(11.8)$ & Reference \\
$\quad \geq 65$ years & 502 & $36(7.2)$ & $0.578(0.365-0.915)$ \\
Dialysis duration & & & \\
$\quad<5$ years & 269 & $40(14.9)$ & Reference \\
$\geq 5$ years & 630 & $43(6.8)$ & $0.421(0.266-0.666)$ \\
\hline Outcome: iPTH within the target range & $N$ & Cases $(\%)$ & OR $(95 \% \mathrm{CI})$ \\
\hline Total & 599 & $390(65.1)$ & \\
iPTH at baseline & & & \\
$\quad \leq 240 \mathrm{pg} / \mathrm{mL}$ & 108 & $78(72.2)$ & Reference \\
$>240$ to $<500 \mathrm{pg} / \mathrm{mL}$ & 359 & $243(67.7)$ & $0.806(0.501-1.296)$ \\
$\geq 500 \mathrm{pg} / \mathrm{mL}$ & 132 & $69(52.3)$ & $0.421(0.245-0.724)$ \\
\hline
\end{tabular}

For both outcomes, logistic regression was performed using the forward-backward stepwise selection method with the following explanatory variables: sex, age, dry weight, baseline serum $\mathrm{iPTH}$, baseline cCa, baseline $\mathrm{P}$, baseline ALP, and dialysis duration $O R$ odds ratio, $C I$ confidence interval, $i P T H$ intact parathyroid hormone, $c C a$ corrected calcium, $P$ phosphorus, $A L P$ alkaline phosphatase

in serum iPTH levels were also associated with maintenance of serum cCa and P levels within appropriate ranges, and an improvement in the serum ALP level. Taken together, these findings demonstrate that long-term administration of etelcalcetide improves the metabolic state of patients with SHPT [7, 9] and the improvement in ALP, in particular, is 
Fig. 4 Changes in serum iPTH levels (a), distribution of serum iPTH levels (b), serum cCa (c), serum $P(\mathbf{d})$, and serum ALP (e) over time. Values are median (quartile 1-quartile 3; a, e), percentage of patients (b), or mean \pm standard deviation (c, d). iPTH intact parathyroid hormone, $S D$ standarddeviation, $c \mathrm{Ca}$ corrected calcium, $P$ phosphorus, $A L P$ alkaline phosphatase
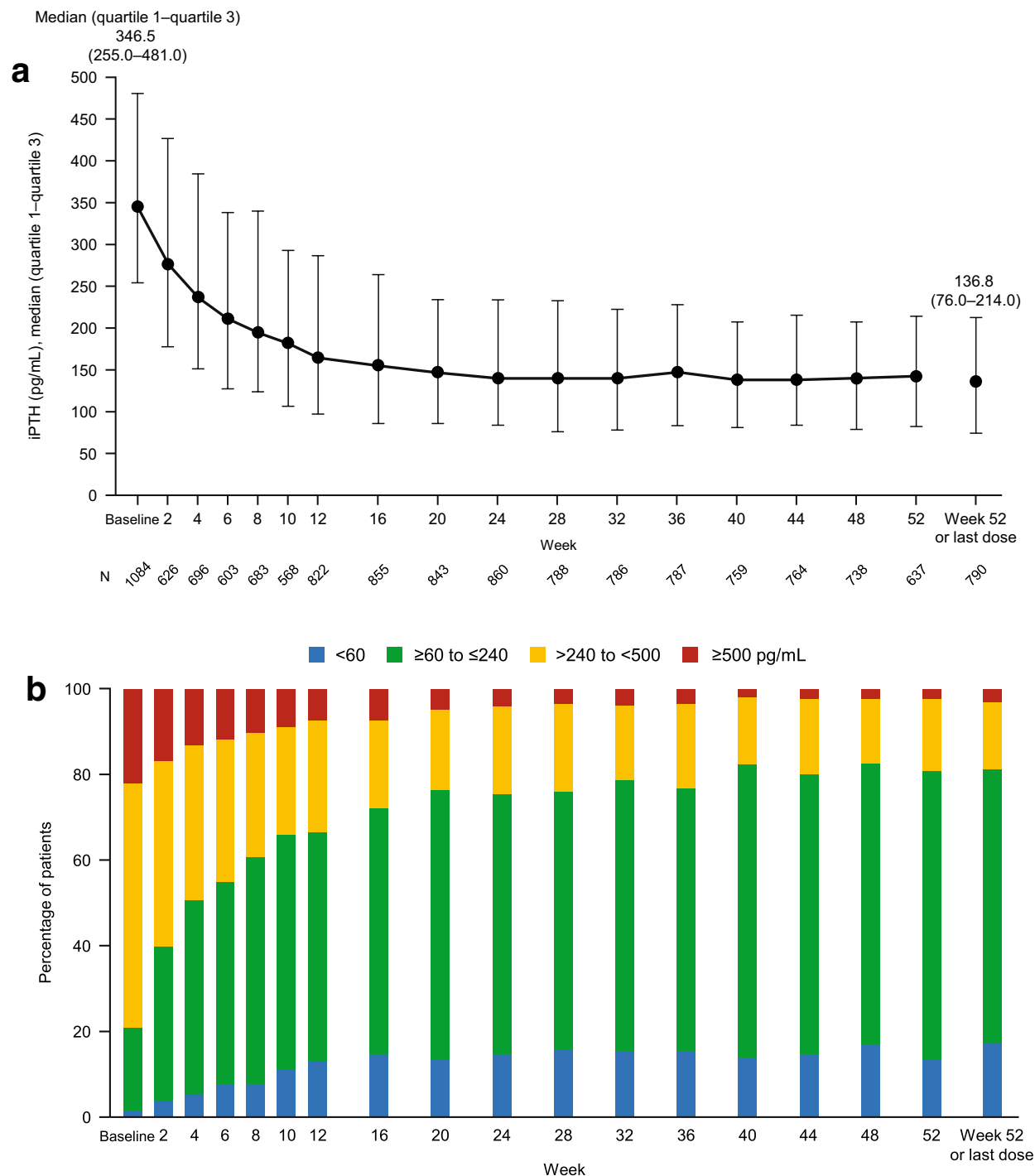

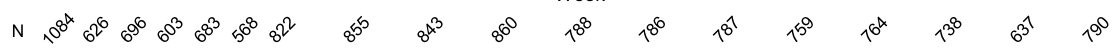

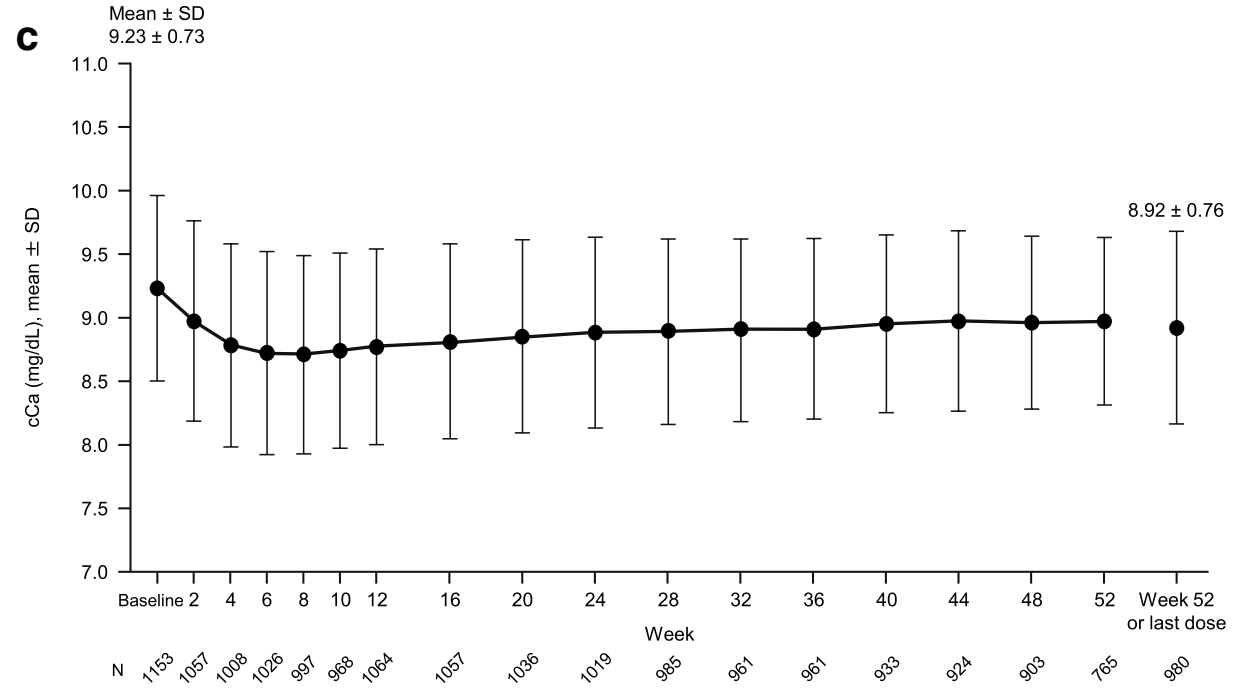


Fig. 4 (continued)
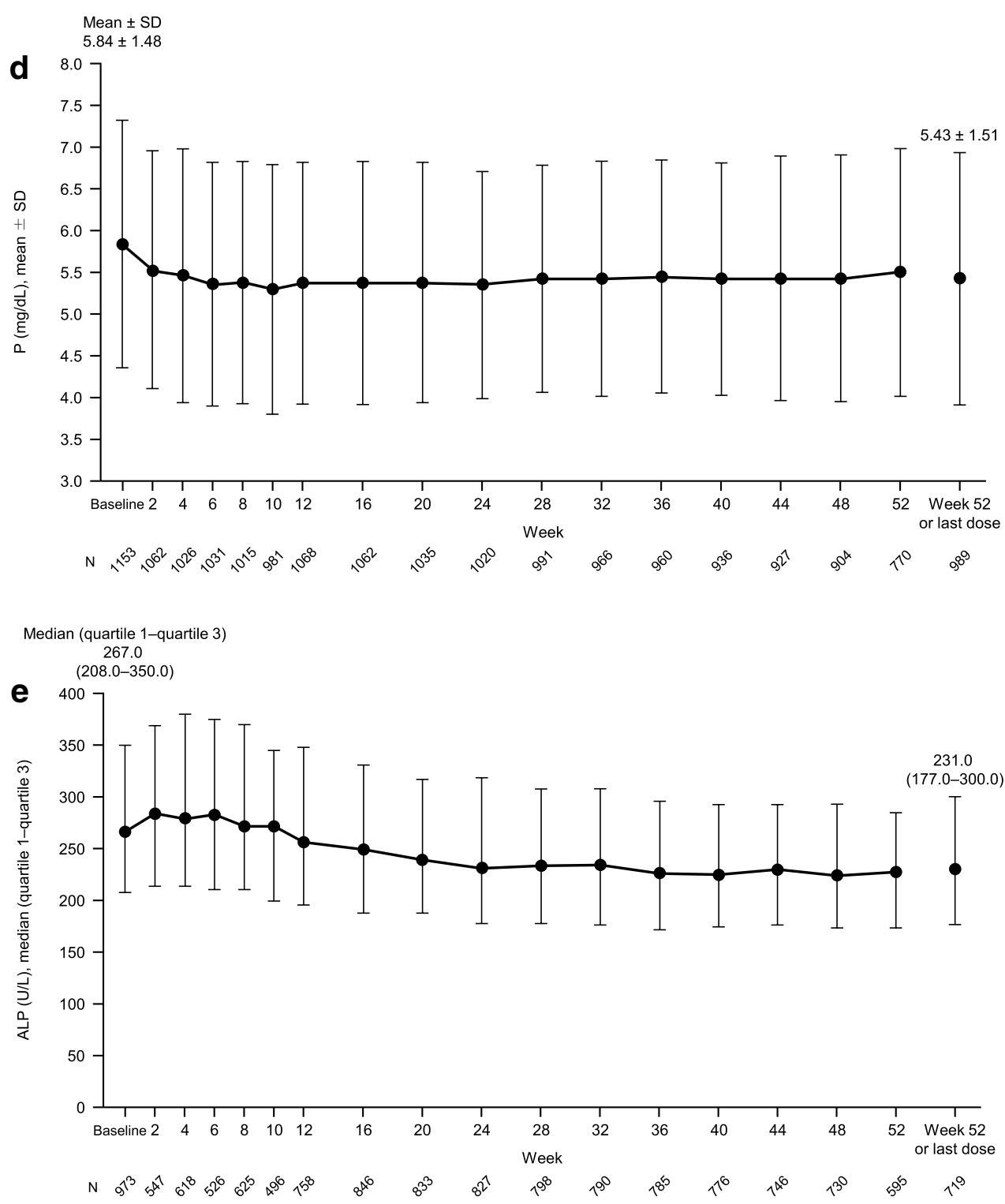

expected to lower the risk of bone disorders and vascular calcification.

We also assessed which baseline factors were associated with achieving target iPTH levels by performing multiple logistic regression. In this analysis, the baseline iPTH level was the only explanatory factor. We found that patients with higher serum iPTH levels at baseline were less likely to achieve iPTH levels within the target range. Furthermore, it took longer for serum iPTH levels to decrease towards the target range in patients with higher baseline iPTH (ESM Fig. 4).

The 52-week study [7] excluded patients whose last dose of cinacalcet was $<28$ days before starting etelcalcetide. In these patients, the serum iPTH levels were lower at baseline and decreased less efficiently than in patients whose last dose of cinacalcet was $\geq 28$ days earlier and in treatment-naïve patients (ESM Fig. 3). These trends may be due to a carryover effect of prior cinacalcet.

Parathyroid gland hyperplasia has emerged as a determinant of unsuccessful treatment of SHPT, including poor outcomes of calcimimetics $[10,11]$. A recent study revealed that dialysis duration, parathyroid gland volume, and serum PTH were risk factors for nodular hyperplasia of parathyroid glands in SHPT [12]. In this PMS, we found that patients with a shorter history of dialysis were more likely to experience hypocalcemia and tended to have lower serum cCa levels, particularly in the first 12 weeks (ESM Fig. 1), but the efficacy of etelcalcetide was comparable (about 60-70\%) in subgroups regardless of dialysis duration. The higher rate of hypocalcemia might be due to higher sensitivity of the parathyroid glands, resulting in greater propensity for lowering Ca levels. Further studies might be necessary to evaluate the impact of parathyroid gland hyperplasia 
Table 5 Subgroup analysis of patients achieving iPTH within the target range (60-240 pg/mL) at Week 52 or last dose $(N=790)$

\begin{tabular}{|c|c|c|c|c|c|}
\hline \multicolumn{3}{|l|}{ Characteristic } & \multicolumn{3}{|c|}{ Proportion achieving target range of iPTH } \\
\hline Variable & Subgroup & $N(\%)$ & $n$ & $\%(95 \% \mathrm{CI})$ & $P$ \\
\hline All patients & & $790(100.0)$ & 506 & $64.1(60.6-67.4)$ & - \\
\hline \multirow[t]{2}{*}{ Sex } & Male & $459(58.1)$ & 292 & $63.6(59.0-68.0)$ & $0.822^{\mathrm{a}}$ \\
\hline & Female & $331(41.9)$ & 214 & $64.7(59.2-69.8)$ & \\
\hline \multirow[t]{4}{*}{ Age (years) } & $<55$ & $189(23.9)$ & 130 & $68.8(61.7-75.3)$ & $0.621^{\mathrm{b}}$ \\
\hline & 55 to $<65$ & $159(20.1)$ & 93 & $58.5(50.4-66.2)$ & \\
\hline & 65 to $<75$ & $282(35.7)$ & 180 & $63.8(57.9-69.4)$ & \\
\hline & $\geq 75$ & $160(20.3)$ & 103 & $64.4(56.4-71.8)$ & \\
\hline \multirow[t]{7}{*}{ Dry body weight (kg) } & $<40$ & $57(7.2)$ & 37 & $64.9(51.1-77.1)$ & $0.364^{\mathrm{b}}$ \\
\hline & 40 to $<50$ & $193(24.4)$ & 127 & $65.8(58.6-72.5)$ & \\
\hline & 50 to $<60$ & $205(25.9)$ & 134 & $65.4(58.4-71.9)$ & \\
\hline & 60 to $<70$ & $173(21.9)$ & 109 & $63.0(55.3-70.2)$ & \\
\hline & 70 to $<80$ & $87(11.0)$ & 52 & $59.8(48.7-70.1)$ & \\
\hline & $\geq 80$ & $70(8.9)$ & 44 & $62.9(50.5-74.1)$ & \\
\hline & Unknown & $5(0.6)$ & 3 & 60.0 & - \\
\hline \multirow[t]{4}{*}{ Baseline iPTH (pg/mL) } & $\leq 240$ & $147(18.6)$ & 107 & $72.8(64.8-79.8)$ & $<0.001^{\mathrm{b}}$ \\
\hline & $>240$ to $<500$ & $428(54.2)$ & 290 & $67.8(63.1-72.2)$ & \\
\hline & $\geq 500$ & $159(20.1)$ & 85 & $53.5(45.4-61.4)$ & \\
\hline & Unknown & $56(7.1)$ & 24 & 42.9 & - \\
\hline \multirow[t]{4}{*}{ Baseline cCa (mg/dL) } & $<8.4$ & $67(8.5)$ & 43 & $64.2(51.5-75.5)$ & $0.278^{\mathrm{b}}$ \\
\hline & 8.4 to 10.0 & $606(76.7)$ & 388 & $64.0(60.1-67.9)$ & \\
\hline & $>10.0$ & $88(11.1)$ & 63 & $71.6(61.0-80.7)$ & \\
\hline & Unknown & $29(3.7)$ & 12 & 41.4 & - \\
\hline \multirow[t]{4}{*}{ Baseline $\mathrm{P}(\mathrm{mg} / \mathrm{dL})$} & $<3.5$ & $20(2.5)$ & 11 & $55.0(31.5-76.9)$ & $0.429^{\mathrm{b}}$ \\
\hline & 3.5 to 6.0 & $427(54.1)$ & 275 & $64.4(59.7-68.9)$ & \\
\hline & $>6.0$ & $314(39.7)$ & 208 & $66.2(60.7-71.5)$ & \\
\hline & Unknown & $29(3.7)$ & 12 & 41.4 & - \\
\hline \multirow[t]{4}{*}{ Baseline ALP (U/L) } & $<160$ & $56(7.1)$ & 39 & $69.6(55.9-81.2)$ & $0.044^{\mathrm{b}}$ \\
\hline & $\geq 160$ to $<320$ & $356(45.1)$ & 240 & $67.4(62.3-72.3)$ & \\
\hline & $\geq 320$ & $215(27.2)$ & 128 & $59.5(52.6-66.2)$ & \\
\hline & Unknown & $163(20.6)$ & 99 & 60.7 & - \\
\hline \multirow[t]{6}{*}{ Dialysis duration (years) } & $<1$ & $60(7.6)$ & 32 & $53.3(40.0-66.3)$ & $0.518^{\mathrm{b}}$ \\
\hline & $\geq 1$ to $<5$ & $177(22.4)$ & 117 & $66.1(58.6-73.0)$ & \\
\hline & $\geq 5$ to $<10$ & $208(26.3)$ & 136 & $65.4(58.5-71.8)$ & \\
\hline & $\geq 10$ to $<20$ & $248(31.4)$ & 156 & $62.9(56.6-68.9)$ & \\
\hline & $\geq 20$ & $81(10.3)$ & 55 & $67.9(56.6-77.8)$ & \\
\hline & Unknown & $16(2.0)$ & 10 & 62.5 & - \\
\hline \multirow[t]{2}{*}{ Dialysis modality } & HD & $538(68.1)$ & 349 & $64.9(60.7-68.9)$ & $0.525^{\mathrm{a}}$ \\
\hline & HDF & $252(31.9)$ & 157 & $62.3(56.0-68.3)$ & \\
\hline \multirow[t]{7}{*}{ Dialysate $\mathrm{Ca}(\mathrm{mEq} / \mathrm{L})$} & $<2.5$ & $2(0.3)$ & 1 & $50.0(1.3-98.7)$ & $0.931^{\mathrm{b}}$ \\
\hline & 2.5 & $250(31.6)$ & 162 & $64.8(58.5-70.7)$ & \\
\hline & $>2.5$ to $<2.75$ & $4(0.5)$ & 3 & $75.0(19.4-99.4)$ & \\
\hline & 2.75 & $272(34.4)$ & 168 & $61.8(55.7-67.6)$ & \\
\hline & 3.0 & $244(30.9)$ & 159 & $65.2(58.8-71.1)$ & \\
\hline & $>3.0$ & $0(0.0)$ & 0 & - & \\
\hline & Unknown & $18(2.3)$ & 13 & 72.2 & - \\
\hline
\end{tabular}


Table 5 (continued)

\begin{tabular}{|c|c|c|c|c|c|}
\hline \multicolumn{3}{|l|}{ Characteristic } & \multicolumn{3}{|c|}{ Proportion achieving target range of iPTH } \\
\hline Variable & Subgroup & $N(\%)$ & $n$ & $\%(95 \% \mathrm{CI})$ & $P$ \\
\hline \multirow[t]{4}{*}{ Time since last dose of cinacalcet (days) } & $<7$ & $263(33.3)$ & 176 & $66.9(60.9-72.6)$ & \multirow[t]{3}{*}{$0.141^{\mathrm{b}}$} \\
\hline & $\geq 7$ to $<28$ & $89(11.3)$ & 61 & $68.5(57.8-78.0)$ & \\
\hline & $\geq 28 /$ cinacalcet-naïve & $427(54.1)$ & 264 & $61.8(57.0-66.5)$ & \\
\hline & Unknown & $11(1.4)$ & 5 & 45.5 & - \\
\hline \multirow[t]{5}{*}{ Last daily dose of cinacalcet $(\mathrm{mg})^{\mathrm{c}}$} & $\leq 25$ & $237(57.2)$ & 161 & $67.9(61.6-73.8)$ & \multirow[t]{4}{*}{$0.944^{\mathrm{b}}$} \\
\hline & $>25$ to $\leq 50$ & $86(20.8)$ & 54 & $62.8(51.7-73.0)$ & \\
\hline & $>50$ to $\leq 75$ & $53(12.8)$ & 41 & $77.4(63.8-87.7)$ & \\
\hline & $>75$ to $\leq 100$ & $36(8.7)$ & 22 & $61.1(43.5-76.9)$ & \\
\hline & Unknown & $2(0.5)$ & 1 & 50.0 & - \\
\hline \multirow[t]{3}{*}{ Liver disease } & No & $733(92.8)$ & 470 & $64.1(60.5-67.6)$ & \multirow[t]{2}{*}{$0.423^{\mathrm{a}}$} \\
\hline & Yes & $44(5.6)$ & 31 & $70.5(54.8-83.2)$ & \\
\hline & Unknown & $13(1.6)$ & 5 & 38.5 & - \\
\hline \multirow[t]{2}{*}{ Diabetes mellitus } & No & $512(61.8)$ & 340 & $66.4(62.1-70.5)$ & \multirow[t]{2}{*}{$0.063^{\mathrm{a}}$} \\
\hline & Yes & $278(35.2)$ & 166 & $59.7(53.7-65.5)$ & \\
\hline
\end{tabular}

$i P T H$ intact parathyroid hormone, $C I$ confidence interval, $c C a$ corrected calcium, $P$ phosphorus, $A L P$ alkaline phosphatase, $H D$ hemodialysis, $H D F$ hemodiafiltration

${ }^{a}$ Fisher's exact test

${ }^{\mathrm{b}}$ Wilcoxon rank sum test

${ }^{\mathrm{c}} N=414$

on the clinical efficacy of etelcalcetide in patients with a long dialysis duration. The serum cCa levels also tracked slightly lower in younger patients (ESM Fig. 2), which might reflect a relationship between younger age and greater parathyroid gland sensitivity/PTH secretory potential [13-16], although this has yet to be confirmed in the context of SHPT.

As in the prior 52-week study [17], we found no differences in the efficacy and safety of etelcalcetide when patients were divided into subgroups according to their dialysate $\mathrm{Ca}$ concentration (Tables 3 and 5).

The results of this PMS support those of the 52-week study, highlighting the long-term tolerability and efficacy of etelcalcetide in real-life clinical practice. Nevertheless, there are some slight differences that might be related to differences in patient eligibility. In particular, this PMS enrolled patients in real-life clinical practice and included patients who were ineligible for the prior study (e.g., last dose of cinacalcet $<28$ days before starting etelcalcetide and baseline serum $\mathrm{cCa}<8.4 \mathrm{mg} / \mathrm{dL}$ ), and there were no specific criteria for adjusting the dose of etelcalcetide or concomitantly used drugs unlike the 52-week study [7].

The real-life use of etelcalcetide was also evaluated in a European observational study performed at 23 dialysis centers in Italy, in which clinicians took into account the KDIGO guidelines to maintain $\mathrm{Ca}, \mathrm{P}$, and PTH levels [8]. Etelcalcetide was administered according to its package insert and started at a dose of $5 \mathrm{mg}$ three-times-weekly, or at another dose if deemed appropriate by the attending clinician. The doses of concomitant medications could also be adjusted if necessary. Of 1190 patients enrolled, 168 received etelcalcetide $(5 \mathrm{mg}$ three-times-weekly), which included 56 calcimimetic-naïve patients. The authors reported low rates of hypocalcemia and gastrointestinal disorders. The serum iPTH level decreased from a median of 636 to $357 \mathrm{pg} / \mathrm{mL}$, while the proportion of responders (defined as iPTH of $150-300 \mathrm{pg} / \mathrm{mL}$ ) increased from 27 to $63 \%$. Significant reductions in serum $\mathrm{Ca}, \mathrm{P}$, and ALP levels were also observed in that study. Since the patient background and management of SHPT differ between European and Japanese studies (e.g., baseline iPTH, target range), we cannot directly compare the results of these studies. Nevertheless, their results of an observational study in a real-world setting provide further evidence in support of our findings, indicating that etelcalcetide is a tolerable and effective intravenous drug for the management of iPTH levels in patients with SHPT on hemodialysis.

\section{Limitations}

The main limitations of this surveillance include its nonrandomized single arm design and that efficacy data were not available for all patients. However, these limitations are partly offset by the large sample size and long-term observation, which enable the detection of rare ADRs and our ability 
to monitor efficacy over a longer period of time than was done in many earlier studies.

\section{Conclusion}

In conclusion, this was the first real-world, large-scale, long-term observational surveillance of etelcalcetide in Japan and involved a much larger cohort of patients than enrolled in prior clinical trials. We did not observe any new safety concerns. Etelcalcetide was associated with clinically relevant improvements in serum iPTH levels together with maintenance of serum $\mathrm{cCa}, \mathrm{P}$, and ALP levels. Intravenous administration of etelcalcetide is a clinically useful treatment for SHPT that avoids the pill burden associated with other treatments and its compliance can be maintained via administration at the dialysis center.

Acknowledgements This surveillance was funded by ONO Pharmaceutical Co., Ltd. The authors thank all physicians and investigators who cooperated in this surveillance. The authors also thank Nicholas D. Smith (EMC K.K.) for medical writing support, which was funded by ONO Pharmaceutical Co., Ltd.

Author contributions KY conceived and designed the study. AT was responsible for data collection. Misato Kuwabara performed data analyses. KY, MF, TS, TA, KY, AT and TA interpreted the data. KY, TA, $\mathrm{KY}$ and AT drafted the manuscript. All authors reviewed the manuscript, approved the final draft, and are accountable for the accuracy and integrity of the manuscript.

Data availability Qualified researchers may request Ono Pharma $(\mathrm{ONO})$ to disclose individual patient-level data from clinical studies through the following website: https://www.clinicalstudydatarequest. com. For more information on ONO's Policy for the Disclosure of Clinical Study Data, please see the following website: https://www. ono.co.jp/eng/rd/policy.html.

\section{Compliance with ethical standards}

Conflict of interest Keitaro Yokoyama has received honoraria from Torii Pharmaceutical Co., Ltd., ONO Pharmaceutical Co., Ltd., and Kyowa Kirin Co., Ltd. Masafumi Fukagawa has received honoraria from ONO Pharmaceutical Co., Ltd., Kyowa Kirin Co., Ltd., and Bayer Yakuhin Ltd.; research grants from Kyowa Kirin Co., Ltd.; and subsidies/donations from Kyowa Kirin Co., Ltd. Takashi Shigematsu has received honoraria from Torii Pharmaceutical Co., Ltd., ONO Pharmaceutical Co., Ltd., Bayer Yakuhin Ltd., Kissei Pharmaceutical Co., Ltd., and Kyowa Kirin Co., Ltd.; research grants from ONO Pharmaceutical Co., Ltd. and Fujiyakuhin Co., Ltd.; and subsidies/donations from ONO Pharmaceutical Co., Ltd., Kyowa Kirin Co., Ltd., and Chugai Pharmaceutical Co., Ltd. Takashi Akiba has nothing to disclose. Ken Yoshikawa, Akira Tsuchiya, and Misato Kuwabara are employees of ONO Pharmaceutical Co., Ltd. Tadao Akizawa has received honoraria from ONO Pharmaceutical Co., Ltd., Torii Pharmaceutical Co., Ltd., Chugai Pharmaceutical Co., Ltd., Kissei Pharmaceutical Co., Ltd., Bayer Yakuhin Ltd., Sanwa Kagaku Kenkyusho Co., Ltd., Astellas Pharma Inc., and Fuso Pharmaceutical Industries, Ltd.; has received fees for serving on advisory boards for Japan Tobacco Inc.,
Kyowa Kirin Co., Ltd., Otsuka Pharmaceutical Co., Ltd., and Nipro Corporation; and has received author fees from Astellas Pharma Inc.

Research involving human participants This surveillance was conducted in accordance with Good Post-marketing Study Practice in Japan, for which the need for ethical approval is waived.

Informed consent Informed consent is not necessary for post-marketing surveillance using anonymized data collected in routine clinical practice for post-marketing evaluation of drug safety.

Open Access This article is licensed under a Creative Commons Attribution 4.0 International License, which permits use, sharing, adaptation, distribution and reproduction in any medium or format, as long as you give appropriate credit to the original author(s) and the source, provide a link to the Creative Commons licence, and indicate if changes were made. The images or other third party material in this article are included in the article's Creative Commons licence, unless indicated otherwise in a credit line to the material. If material is not included in the article's Creative Commons licence and your intended use is not permitted by statutory regulation or exceeds the permitted use, you will need to obtain permission directly from the copyright holder. To view a copy of this licence, visit http://creativecommons .org/licenses/by/4.0/.

\section{References}

1. Cunningham J, Locatelli F, Rodriguez M. Secondary hyperparathyroidism: pathogenesis, disease progression, and therapeutic options. Clin J Am Soc Nephrol. 2011;6(4):913-21.

2. Silver J, Kilav R, Naveh-Many T. Mechanisms of secondary hyperparathyroidism. Am J Physiol Renal Physiol. 2002;283(3):F367-76.

3. Kidney Disease: Improving Global Outcomes (KDIGO) CKDMBD Update Work Group. KDIGO 2017 clinical practice guideline update for the diagnosis, evaluation, prevention, and treatment of chronic kidney disease-mineral and bone disorder CKD-MBD. Kidney Int Suppl (2011). 2017;7(1):1-59.

4. Fukagawa M, Yokoyama K, Koiwa F, Taniguchi M, Shoji T, Kazama JJ, et al. Clinical practice guideline for the management of chronic kidney disease-mineral and bone disorder. Ther Apher Dial. 2013;17(3):247-88.

5. Hamano N, Komaba H, Fukagawa M. Etelcalcetide for the treatment of secondary hyperparathyroidism. Expert Opin Pharmacother. 2017;18(5):529-34.

6. Wu B, Melhem M, Subramanian R, Chen P, Jaramilla Sloey B, Fouqueray B, et al. Clinical pharmacokinetics and pharmacodynamics of etelcalcetide, a novel calcimimetic for treatment of secondary hyperparathyroidism in patients with chronic kidney disease on hemodialysis. J Clin Pharmacol. 2018;58(6):717-26.

7. Shigematsu T, Fukagawa M, Yokoyama K, Akiba T, Fujii A, Odani M, et al. Long-term effects of etelcalcetide as intravenous calcimimetic therapy in hemodialysis patients with secondary hyperparathyroidism. Clin Exp Nephrol. 2018;22(2):426-36.

8. Russo D, Tripepi R, Malberti F, Di Iorio B, Scognamiglio B, Di Lullo L, et al. Etelcalcetide in patients on hemodialysis with severe secondary hyperparathyroidism. Multicenter study in "real life". J Clin Med. 2019;8(7):1066.

9. Shigematsu T, Fukagawa M, Yokoyama K, Akiba T, Fujii A, Odani M, et al. Effects of the intravenous calcimimetic etelcalcetide on bone turnover and serum fibroblast growth 
factor 23: post hoc analysis of an open-label study. Clin Ther. 2018;40(12):2099-111.

10. Sumida K, Nakamura M, Ubara Y, Marui Y, Tanaka K, Takaichi $\mathrm{K}$, et al. Histopathological alterations of the parathyroid glands in haemodialysis patients with secondary hyperparathyroidism refractory to cinacalcet hydrochloride. J Clin Pathol. 2011;64(9):756-60.

11. Vulpio C, Bossola M, Di Stasio E, Tazza L, Silvestri P, Fadda G. Histology and immunohistochemistry of the parathyroid glands in renal secondary hyperparathyroidism refractory to vitamin D or cinacalcet therapy. Eur J Endocrinol. 2013;168(6):811-9.

12. Jäger MD, Serttas M, Beneke J, Müller JA, Schrem H, Kaltenborn A, et al. Risk-factors for nodular hyperplasia of parathyroid glands in sHPT patients. PLoS ONE. 2017;12(10):e0186093.

13. Halloran B, Udén P, Duh Q-Y, Kikuchi S, Wieder T, Cao J, et al. Parathyroid gland volume increases with postmaturational aging in the rat. Am J Physiol Endocrinol Metab. 2002;282(3):E557-63.
14. Halloran BP, Lonergan ET, Portale AA. Aging and renal responsiveness to parathyroid hormone in healthy men. J Clin Endocrinol Metab. 1996;81(6):2192-7.

15. Portale AA, Lonergan ET, Tanney DM, Halloran BP. Aging alters calcium regulation of serum concentration of parathyroid hormone in healthy men. Am J Physiol. 1997;272(1 Pt 1):E139-46.

16. Tejwani V, Qian Q. Calcium regulation and bone mineral metabolism in elderly patients with chronic kidney disease. Nutrients. 2013;5(6):1913-36.

17. Shigematsu T, Fukagawa M, Yokoyama K, Akiba T, Fujii A, Shinoda $\mathrm{A}$, et al. Influence of dialysate $\mathrm{Ca}$ concentrations on the therapeutic effects of etelcalcetide with concomitant drugs in patients with secondary hyperparathyroidism. Nephrology (Carlton). 2020;25(8): 634-43.

Publisher's Note Springer Nature remains neutral with regard to jurisdictional claims in published maps and institutional affiliations. 